\title{
DOCUMENTO Por um Plano Nacional de Educação (2011-2020) como política de Estado
}

\author{
DALILA ANDRADE OLIVEIRA \\ Presidente da ANPEd \\ Universidade Federal de Minas Gerais \\ LUIZ FERNANDES DOURADO \\ Universidade Federal de Goiás \\ ANTONIO CABRAL NETO \\ Vice-Presidente da ANPEd \\ Universidade Federal do Rio Grande do Norte \\ CARLOS ROBERTO JAMIL CURY \\ Pontifícia Universidade Católica de Minas Gerais \\ JOÃO FERREIRA DE OLIVEIRA \\ Vice-Preseidente da ANPEd \\ Universidade Federal de Goiás \\ JOSÉ MARCELINO DE REZENDE PINTO \\ Universidade de São Paulo \\ LIVIA MARIA FRAGA VIEIRA \\ Universidade Federal de Minas Gerais \\ MARIA MARGARIDA MACHADO \\ Universidade Federal de Goiás \\ NILMA LINO GOMES \\ Universidade Federal de Minas Gerais
}

\section{INTRODUÇÃO}

Iniciamos a segunda década do século XXI com um desafio da mais alta relevância para o futuro do Brasil, o que nos impõe uma necessidade imediata e objetiva: aprovar o Plano Nacional de Educação (PNE) como política de Estado para os próximos dez anos (2011-2020).

Em 2010, foi realizada a Conferência Nacional de Educação (CONAE), que se constituiu em amplo movimento envolvendo a sociedade política e diversos setores da sociedade civil vinculados à educação. Ocorrida em Brasília, entre os dias 
28 de março e $1^{\circ}$ abril de 2010, a CONAE foi um processo de debate democrático que possibilitou a participação efetiva de diversos segmentos, discutindo os rumos da educação brasileira - da creche à Pós-Graduação - para retirar daí os subsídios necessários à elaboração do Plano Nacional de Educação (PNE) para os próximos dez anos.

A CONAE foi precedida de conferências municipais, regionais e estaduais que contaram com a participação de professores e outros profissionais da educação, estudantes, pais, gestores, pesquisadores, diversos sujeitos e segmentos organizados em torno da educação. A ANPEd participou ativamente do processo de organização da CONAE, representando as entidades de estudos e pesquisa em Educação: Associação Nacional pela Formação dos Profissionais da Educação (ANFOPE), Associação Nacional de Política e Administração da Educação (ANPAE) e Centro de Estudos Educação e Sociedade (CEDES), Fórum dos Diretores das Faculdades de Educação (FORUMDIR) bem como do debate que a precedeu em diferentes estados e municípios do Brasil, por meio da participação direta de seus associados.

Assim, nossa Associação tem buscado contribuir com a educação brasileira aportando ao debate o conhecimento acumulado e veiculado em nossos espaços acadêmicos e políticos, seja pela colaboração direta dos nossos associados como pesquisadores e estudiosos da educação em suas múltiplas especificidades, seja por meio da articulação com outras entidades da sociedade civil, procurando entendimentos e a constituição de consensos que possam viabilizar a construção de um futuro melhor.

O Projeto de Lei (PL n. 8.035) apresentado pelo Governo Federal ao Congresso Nacional em dezembro de 2010, ora em tramitação na Câmara Federal, em Comissão Especial constituída para esse fim, não refletiu o conjunto das decisões da CONAE. Os avanços contidos no documento final da CONAE, resultado dos debates e disputas internas ocorridos no espaço democrático de discussão que esta possibilitou, não foram, em sua maioria, contemplados no PL n. 8.035/2010. Além disso, o referido projeto apresenta outros problemas que precisam ser identificados e resolvidos para que possamos aprovar no Congresso Nacional um PNE que atenda aos anseios da sociedade brasileira. Dentre esses problemas, merece ser destacada a necessidade de maior organicidade entre as metas e as estratégias propostas, em sintonia com o documento final da CONAE.

Diante disso, a ANPEd promoveu ampla discussão entre seus associados por meio dos Grupos de Trabalho (GT), estimulando cada GT a apresentar suas contribuições, sobretudo, nas matérias específicas a que cada grupo se dedica.

Nossa iniciativa pautou-se no entendimento de que a pesquisa deve estar a serviço do bem comum e que é nosso dever como associação acadêmica colocar à disposição da política a produção científica acumulada nesses nossos mais de 34 anos de existência. Compreendemos que é com conhecimento socialmente referenciado que construiremos hoje o amanhã e que a excelência acadêmica não é relevante socialmente se não tiver a serviço da vida, da paz e da felicidade humana. 
A partir das colaborações vindas dos GTs, constituímos uma comissão, composta por pares, especialistas em diferentes níveis, etapas e modalidades da educação, para produzir um documento-síntese que refletisse nossa posição diante do PL n. 8035/2010 e apresentasse de forma sistematizada nossas contribuições ao novo PNE. Para a consolidação desse trabalho, a comissão estabeleceu diálogo com as contribuições da área atinentes à avaliação da proposta de PNE 2011-2020. Destacaram-se, nesse processo, sobretudo, estudo minucioso e consideração às análises e propostas de emenda ao PL n. 8035/2010: apresentadas pela Campanha Nacional pelo direito à Educação, pela Confederação Nacional dos Trabalhadores em Educação (CNTE) e pelo Centro de Estudos Educação e Sociedade (CEDES).

Nesta seção Documentos da Revista Brasileira de Educação (RBE), socializamos, a seguir, uma síntese deste documento da ANPEd denominado "Por Um Plano Nacional de Educação (2011-2020) como Política de Estado" "1 que foi apresentado à sociedade brasileira como uma contribuição da maior associação científica da área de educação, que contempla em seu interior mais de uma centena de programas de pós-graduação em educação e mais de três mil pesquisadores. Nosso objetivo ao dar publicidade a esse documento é contribuir para o debate em torno das melhorias necessárias ao PL n. 8035/2010 em tramitação.

Entendemos, contudo, que é por meio da articulação com outras associações e sociedades científicas, entidades e movimentos sociais interessados na edificação de um PNE como política de Estado que conseguiremos assegurar uma educação pública, democrática, laica e de qualidade como direito social para todos e todas e para o futuro deste país. A ANPEd entende que esse direito se realiza no contexto desafiador de superação das desigualdades e do reconhecimento e respeito à diversidade.

Nesse sentido, esta produção da ANPEd é um convite ao debate, à construção de estratégias de mobilização que congreguem a todos e todas que, individual ou coletivamente, queiram somar-se a esse movimento. A ANPEd compreende que cumpre um papel importante na dinâmica social, ao buscar interferir politicamente nos rumos da educação brasileira, disponibilizando seu acúmulo histórico conquistado - seu maior patrimônio.

\section{O DOCUMENTO ANPEd E AS SUGESTÕES AO PL N. 8.035/2010}

O documento produzido pela ANPEd analisa e faz sugestões à proposta de PNE do Executivo Federal (PL n. 8.035/2010), em tramitação no Congresso

1 Foi produzido pela ANPEd um caderno intitulado "Por Um Plano Nacional de Educação (2011-2020) como Política de Estado”. A referida produção foi lançada durante o XXV Simpósio Brasileiro de Política e Administração e II Congresso Ibero-Americano de Política e Administração da Educação na PUCC/SP no dia 29/4/2011 e encontra-se disponível para consulta no site da ANPEd (http://www.anped.org.br/). 
Nacional, considerando o debate acumulado, a produção científica e o engajamento da ANPEd nas lutas em prol de uma educação pública, gratuita, laica e de qualidade para todos, e em articulação com outras entidades científicas, sindicais e fóruns nacionais.

Ao longo de 34 anos de existência, a ANPEd vem contribuindo para a produção de estudos e pesquisas que analisam, propõem e avaliam as políticas de Estado para a educação nacional, em todos os seus níveis, etapas e modalidades.

A Associação sempre enfatizou a necessidade da mobilização e da participação da sociedade civil na construção coletiva das políticas de Estado, incluindo a defesa de que a elaboração do novo PNE (2011-2020) seja a expressão do efetivo processo de participação e construção coletiva, envolvendo as sociedades civil e política.

\section{PRINCÍPIOS E ATUAÇÃO DA ANPEd NA PRODUÇÃO DO CONHECIMENTO, NA AVALIAÇÃO E PROPOSIÇÃO DE POLÍTICAS NO CAMPO DA EDUCAÇÃO}

A ANPEd tem-se constituído, desde seu nascimento, em fórum cativo de debates das questões científicas, éticas e políticas da área, consolidando-se, dessa forma, em referência básica para a produção do conhecimento, na medida em que sua atuação vem pautando-se pela busca do desenvolvimento científico e pelo compromisso com a democratização e melhoria da educação brasileira.

Em suas lutas, a ANPEd participou ativamente da construção da proposta de PNE - denominada Proposta da Sociedade Brasileira - por meio de suas reuniões anuais, dos Congressos Nacionais de Educação (CONEDs), e do Fórum Nacional em Defesa da Escola Pública. Essa proposta de Plano foi derrotada, no processo legislativo nacional, resultando na aprovação, em 2001, da proposta de PNE encaminhada pelo Executivo Federal (Lei n. 10.172/2001). É importante destacar que as duas propostas expressavam projetos educacionais distintos, sobretudo na abrangência das políticas, seu financiamento e gestão. $\mathrm{O}$ PNE aprovado, com a incidência de nove vetos presidenciais, em sua maioria, concernentes ao financiamento, não se efetivou como política de Estado e foi secundarizado como política de governo.

A realização de conferências nacionais de educação básica, educação indígena, educação tecnológica, entre outras, na segunda metade dos anos 2000, propiciaram as condições políticas para a realização da Conferência Nacional de Educação (CONAE), em Brasília, no período de 28 de março a $1^{\circ}$ de abril de 2010, conferência esta precedida de conferências municipais, regionais, estaduais que foram marcadas por significativa participação da sociedade civil organizada. A CONAE pautou, em seu documento final, as bases para o PNE a partir de suas deliberações, constituindo-se, desse modo, em referencial político e marco 
para a educação nacional e para as políticas de Estado. A ANPEd participou ativamente desse processo, em todos os momentos.

A participação da ANPEd em diversos fóruns e espaços (incluindo participação ativa na Comissão Organizadora da CONAE e, em 2011, no recém-criado Fórum Nacional de Educação (FNE), e nos diversos momentos de rearticulação do Fórum Nacional em Defesa da Escola Pública (FNEDEP)) está em sintonia com um conjunto de princípios historicamente construídos pela Associação, partindo do pressuposto de que o direito à educação para todos e todas deve ser garantido por meio:

a | da defesa da educação pública, gratuita, democrática laica e de qualidade social para todos e todas;

b | do esforço por articular o direito à igualdade e o direito à diferença, colocando-se, portanto, a favor de um pluralismo democrático consequente;

c | da universalização do acesso à educação para crianças, jovens e adultos, em todos os níveis e modalidades da educação;

d | da luta pela permanência de crianças, jovens e adultos em instituições educativas de qualidade, na qual se garanta a inclusão de todos e todas, mediante a promoção de um efetivo processo de ensino e aprendizagem;

e | da efetivação de políticas contra formas associadas de exclusão, motivadas por preconceito e discriminação de natureza étnico-racial, de orientação sexual ou de identidade de gênero ou de qualquer outra decorrente de conteúdos ou condutas incompatíveis com a dignidade humana;

f | da definição e realização de políticas que promovam melhores condições de oferta da educação básica e superior, ampliando e garantindo padrões de qualidade à educação socialmente referenciada;

$\mathrm{g}$ | da aplicação do conhecimento científico e da tecnologia nas atividades pedagógicas, em prol da construção de uma educação de qualidade no país;

$\mathrm{h} \mid$ da defesa de uma formação docente, inicial e continuada, capaz de preparar profissionais da educação que se destaquem pelo espírito científico, pela criatividade, pela competência técnica, pela atitude ética e pelo posicionamento político autônomo;

i | da garantia de adequadas condições de trabalho, de carreira e de salário para os profissionais da educação;

j | do desenvolvimento de um sistema nacional de pós-graduação em permanente aperfeiçoamento e em consonância com as necessidades do país;

$\mathrm{k} \mid$ do incentivo à entrada crescente de jovens e adultos bem preparados em cursos de licenciatura;

1 | da definição precisa de organização e funcionamento do sistema nacional de educação, a partir de políticas, programas e ações, que concretizem o regime de colaboração entre os entes federados;

$\mathrm{m} \mid$ do incentivo e promoção das artes e da cultura nos diferentes espaços de formação humana, escolares e não escolares; 
n | da democratização efetiva do acesso e permanência na educação básica e superior de qualidade e nas lutas em prol da democratização da gestão educacional.

Como associação científica de educação no país, a ANPEd propõe-se, com este documento, reafirmar os princípios que balizam sua atuação de entidade ímpar na área educacional, contribuindo, efetivamente, para a rediscussão e o avanço dos marcos político-pedagógicos e financeiros do PL n. 8.035/2010, pelo estabelecimento de um PNE de Estado que realmente contribua para a melhoria e a democratização das políticas e processos de organização e gestão da educação básica e superior, bem como de suas modalidades educativas.

\section{A AVALIAÇÃO CRÍTICO-PROPOSITIVA DA ANPEd SOBRE O PL N. 8.035/2010}

A avaliação crítico-propositiva da ANPEd, em articulação com diversos espaços, movimentos, documentos e discussões do campo educacional, especialmente aqueles envolvendo outras entidades científicas e sindicais da área, tais como: ANFOPE, ANPAE, CEDES, CNTE, Sindicato Nacional dos Docentes das Instituições de Ensino Superior (ANDES-SN), bem como, Campanha Nacional pelo Direito à Educação, entre outros, procura contribuir com este importante momento político de definição das bases, diretrizes, metas e estratégias para o PNE, para o período de 2011 a 2020, o qual, por sua vez, incidirá sobre os demais planos decenais de educação a serem construídos (municipais, estaduais e do Distrito Federal).

A ANPEd entende que o cumprimento de seus princípios implica o estabelecimento de políticas de Estado, cuja elaboração requer a participação ampla e democrática da sociedade civil, visando realizar e garantir - com qualidade - os direitos educacionais para todos e todas. Com esse objetivo, vem acompanhando atentamente a tramitação do PL n. 8.035/2010 no Congresso Nacional, empenhando-se pela ampliação dos debates, em diferentes espaços, e a realização de audiências públicas, a fim de garantir sua efetiva discussão e melhoria.

Para consolidar este posicionamento histórico, a ANPEd mobilizou os seus 23 grupos de trabalho a apresentarem contribuições por meio da discussão coletiva entre seus membros, especialistas em diferentes aspectos que compõem a educação, e constituiu uma comissão especial para realizar a avaliação da proposta de PL n. 8.035/2010, a fim de apresentar contribuição qualitativa, a partir da incorporação das sugestões vindas de seus GTs e das contribuições da área, e produzir um documento crítico-propositivo.

Tal entendimento e encaminhamento político parte da premissa básica de que o PL n. 8.035/2010 apresenta alguns avanços, sobretudo no estabelecimento de diretrizes e metas de universalização (dos 4 aos 17 anos), como requer a Constituição Federal, por meio da Emenda Constitucional n. 59/2009. Mas considera, 
ao mesmo tempo, que a proposta de Plano não traduz o conjunto das deliberações aprovadas pela CONAE, apresentando limites na organização, concepção de metas, articulação entre metas e estratégias etc.

Outro aspecto limitador desse Projeto de Lei consiste na ausência de diagnóstico da realidade educacional brasileira, bem como dos processos avaliativos efetivados sobre o cumprimento das metas do PNE 2001-2010.

Tudo isso mostra a importância de avançarmos na construção do PNE 2011-2020, para garantir que ele seja expressão de políticas de Estado, balizadas pelo pacto federativo e pela regulamentação do regime de colaboração e cooperação entre os entes federados, como preconiza a CF de 1988. Faz-se necessário avançar, ainda, na instituição e consolidação de um sistema nacional de educação contribuindo para a garantia de educação pública, gratuita, laica, democrática, inclusiva e de qualidade social para todos e todas e para a universalização do acesso, ampliação da jornada escolar e a garantia da permanência bem-sucedida para crianças, adolescentes, jovens e adultos, em todos os níveis, etapas e modalidades. A ANPEd entende que esse direito se realiza no contexto desafiador de superação das desigualdades e do reconhecimento e respeito à diversidade. A tramitação do PL n. 8.035/2010 exige ampla mobilização, para garantir avanços na proposta em discussão.

A participação efetiva da ANPEd como entidade titular pretende a consolidação do Fórum Nacional de Educação (FNE) como espaço de discussão, proposição e avaliação das políticas educacionais, bem como espaço de mobilização social.

Juntamente com as entidades que compõem o Fórum, ${ }^{2}$ a ANPEd posicionou-se favorável à primeira manifestação pública do FNE, por meio de nota à sociedade

2 Órgãos e entidades presentes na primeira reunião ordinária do Fórum Nacional de Educação (28.03.11): Associação Brasileira das Universidades Comunitárias (ABRUC); Associação Brasileira dos Reitores das Universidades Estaduais e Municipais (ABRUEM); Associação Nacional de Pós-Graduação e Pesquisa em Educação (ANPEd); Campanha Nacional pelo Direito à Educação; Central Unica dos Trabalhadores (CUT); Comissão Técnica Nacional de Diversidade para Assuntos Relacionados à Educação dos Afro-brasileiros (CADARA); Confederação Nacional das Associações de Pais e Alunos (CONFENAPA); Confederação Nacional dos Estabelecimentos de Ensino (CONFENEN); Confederação Nacional dos Trabalhadores em Educação (CNTE); Confederação Nacional dos Trabalhadores em Estabelecimentos de Ensino (Contee); Confederação Nacional dos Trabalhadores na Agricultura (CONTAG); Confederação Nacional do Comércio (CNC); Conselho Nacional das Instituições da Rede Federal de Educação Profissional, Científica e Tecnológica (CONIF); Conselho Nacional de Educação (CNE); Conselho Nacional de Secretários de Educação (CONSED); Federação de Sindicatos de Trabalhadores de Universidades Brasileiras (Fasubra); Fórum de Professores das Instituições Federais de Ensino (Proifes); Fórum Nacional dos Conselhos Estaduais de Educação (FNCEE); Ministério da Educação (MEC); Sindicato Nacional dos Servidores Federais da Educação Básica, Profissional e Tecnológica (SINASEFE); Sociedade Brasileira para o Progresso da Ciência (SBPC); União Brasileira dos Estudantes Secundaristas (UBES); União Nacional dos Conselhos Municipais de Educação (UNCME); União Nacional dos Dirigentes Municipais de Educação (UNDIME); União Nacional dos Estudantes (UNE). 
brasileira e ao Congresso Nacional, em que, respeitando a soberania e a independência do Poder Legislativo, defendeu a tramitação do PNE 2011-2020 com base nos seguintes princípios:

1 | A Comissão Especial, na qual irá tramitar o PL n. 8035/2010, deve ter a participação majoritária de parlamentares dedicados e comprometidos com a causa da educação, privilegiando membros da Comissão de Educação e Cultura da Câmara dos Deputados.

2 | A tramitação do PL n. 8035/2010 deve ser célere, sem ser aligeirada, com a preocupação essencial de que haja qualidade nos debates em torno da matéria, tão importante ao país.

3 | A tramitação do PL n. 8035/2010 deve ser democrática e participativa, compreendendo um amplo cronograma de audiências públicas capazes de garantir a necessária capilaridade e legitimidade ao futuro mecanismo legal de planejamento da educação brasileira. Os debates em torno do PL n. 8035/2010 devem tomar como referência primordial as deliberações da CONAE. O Fórum Nacional de Educação solicitou à futura Comissão Especial e à Comissão de Educação e Cultura da Câmara dos Deputados a realização de audiências públicas para se debater a proposta do PNE à luz do documento final da CONAE.

Outra importante deliberação do FNE foi a de contribuir para a organização de fóruns estaduais, distrital e municipais para que o PL n. 8035/2010 seja debatido com a maior capilaridade possível, fortalecendo a legitimidade do futuro PNE.

Por último, o Fórum Nacional de Educação entendeu ser essencial o estabelecimento de uma interlocução intensa entre a dimensão nacional e as dimensões estadual, distrital e municipal para o fortalecimento do PNE 2011-2020. O objetivo é garantir a devida abrangência federativa a um Plano de ampla envergadura e escopo.

Considerando os movimentos em defesa da ampla participação da sociedade civil, a ANPEd vem atuando junto ao Fórum Nacional em Defesa da Escola Pública (FNDEP) e com ações destinadas a avançar na construção do PNE como política de Estado, o que foi reafirmado em recente aprovação da carta de princípios $(\mathrm{FNDEP})^{3}$ pelas entidades participantes.

3 O FNDEP constitui-se em uma articulação de entidades e movimentos sociais organizados da sociedade brasileira, com representação nacional, que partilhando princípios, valores, concepções e ideais, buscam defender, de forma autônoma e independente, a educação pública, estatal, gratuita, democrática, laica e de qualidade social, para todos os cidadãos e cidadãs brasileiros(as).

São princípios do FNDEP:

I. Educação como direito de todos e dever do Estado;

II. Educação fundada na democracia, na ética, na solidariedade, no diálogo, no respeito aos direitos humanos e na busca incessante de justiça social; 
A participação ativa da ANPEd em todos esses processos, articulados às contribuições das entidades da área e dos grupos de trabalho da Associação, resultou no documento de avaliação do PL n. 8.035/2010 e no encaminhamento de proposições para contribuir no aprimoramento do PNE 2001-2020, à luz dos princípios historicamente construídos pela associação.

Assim, o documento ANPEd apresentou sugestões à lei que institui o PL n. 8.035/2010, especialmente quanto às suas diretrizes, bem como ao anexo, envolvendo as 20 metas e 170 estratégias $\mathrm{O}$ documento apresenta-se estruturado em introdução (PNE como política de Estado), propostas de emendas ao PL (lei, metas e estratégias). Neste documento a ANPEd ratifica o seu compromisso com a educação pública, gratuita, laica e de qualidade como base para o estabelecimento de políticas de Estado para a democratização do direito à educação e a melhoria da qualidade da educação para todos.

\section{CONSIDERAÇÕES FINAIS}

Entendendo a importância da construção coletiva de um pacto social pela melhoria da qualidade da educação brasileira e a legitimidade do processo de aprovação do documento final da CONAE, que foi precedido de debates estaduais e municipais sobre o documento referência produzido pela comissão nacional e submetido à apreciação e aprovação dos delegados nas diferentes instâncias e na plenária nacional da CONAE, a ANPEd reafirma a necessidade de que o debate sobre o PNE respeite as deliberações da CONAE e a necessidade da defesa dos seguintes princípios lá inscritos:

a | ampliação de recursos para educação tendo como meta a aplicação de $10 \%$ do PIB em educação até 2020;

b | destinação de recursos públicos exclusivamente para instituições públicas de ensino;

c | gestão democrática do sistema de ensino e das instituições educativas tendo como instrumentos a eleição de diretores e a existência de conselhos escolares ou colegiados deliberativos, dentre outros;

d | necessidade do incremento da qualidade da escola mediante a adoção do custo-aluno qualidade (CAQ) como referência para o financiamento;

III. Pluralismo de ideias e de convicções e a liberdade de expressá-las;

IV. Liberdade de aprender, de ensinar, de pesquisar, de acesso ao patrimônio intelectual - científico, técnico, tecnológico, artístico, filosófico, cultural - da humanidade;

v. Organização de um sistema nacional de educação, público, unitário e planejado, de modo a assegurar os interesses do conjunto da sociedade;

VI. Educação escolar como direito fundamental de desenvolvimento individual, social, cultural, político e econômico do país, de modo que garanta à população os direitos de cidadania; 
e | respeito à pluralidade de ideias e concepções pedagógicas incentivando as escolas para a elaboração de seu projeto político-pedagógico;

$\mathrm{f}$ | formação e valorização dos/das profissionais da educação mediante a garantia de formação inicial e continuada, instituição de Planos de Cargos, Carreira e Remuneração (PCCR), que garantam um piso salarial profissional nacional articulado ao custo-aluno qualidade, com garantias de jornada de trabalho em uma única instituição educativa, com tempo destinado à formação e planejamento, com condições dignas de trabalho e definição de um número máximo de estudantes por turma e por professor;

g | o reconhecimento do papel estratégico das instituições da educação básica e superior na construção de uma nova ética, centrada na vida, no mundo do trabalho, na solidariedade e numa cultura da paz, superando as práticas opressoras, de modo que inclua, efetivamente, os grupos historicamente excluídos: negros, quilombolas, pessoas com deficiência, povos indígenas, trabalhadores do campo, mulheres, LGBTT (lésbicas, gays, bissexuais, travestis e transexuais), entre outros.

E, por fim, por uma política de pós-graduação que seja guiada pelos princípios democráticos que devem orientar a organização e gestão do Sistema Nacional de Educação que promova o desenvolvimento científico com compromisso social.

Abril de 2011.

VII. Financiamento pelo poder público, para garantir o exercício do direito à educação de qualidade, nos seus níveis e modalidades, assegurando que as verbas públicas destinadas à educação sejam exclusivas para as instituições públicas;

VIII. Gestão democrática nos sistemas e instituições educacionais;

IX. Garantia de formação inicial presencial e de oportunidades sistemáticas de formação continuada para os profissionais da educação;

X. Valorização dos profissionais da educação por meio de ingresso na carreira por concurso público, planos de carreira, piso salarial profissional e condições adequadas de trabalho;

XI. Solidariedade nacional e internacional na luta pelo direito à educação pública, gratuita, democrática, laica e de qualidade nos seus níveis e modalidades e pela universalização do patrimônio intelectual da humanidade;

XII. Indissociabilidade entre ensino, pesquisa e extensão na educação nacional. 